HELMINTHOLOGIA, 56, 2: 108 - 117, 2019

\title{
Intestinal parasites of pets and other house-kept animals in Moscow
}

\author{
O. P. KURNOSOVA, M. V. ARISOV* I. M. ODOYEVSKAYA
}

All-Russian Scientific Research Institute of Fundamental and Applied Parasitology of Animals and Plants named after K.I. Skryabin Branch of the Federal State Budget Scientific Institution «Federal Scientific Center - All- Russian Scientific Research Institute of Experimental Veterinary Medicine named after K.I. Skryabin and Y.R. Kovalenko the Russian Academy of Sciences», 28, Bolshaya Cheremushkinskaya street, Moscow, Russia, 117218, *E-mail: director@vniigis.ru

Article info

Received August 23, 2018

Accepted March 1, 2019

\section{Summary}

A study screening pet animals (dogs, cats, chinchillas, ferrets, guinea pigs, rabbits, primates, reptiles, and hedgehogs) within Moscow city limits for intestinal parasitic diseases has been conducted over a period of 6 years. According to the study, parasitic infections caused by intestinal protozoa are found in pet animals more frequently than by intestinal helminths. Although dogs and cats exhibit the highest level of diversity of intestinal parasite species, in the group of exotic animals, helminth infection are found much less frequently and parasitic fauna is represented mostly by intestinal protozoa with a high percentage of mixed infection. The most widespread helminth infection of dogs and cats is toxocarosis (respectively 2.5 and $5.7 \%$ ) and the most widespread protozoan infection is Giardia sp. (9.8 and $4.6 \%$ ). Giardia sp. was found in $47.4 \%$ of chinchillas, Cryptosporidium sp. was more frequently found in ferrets $(6.55 \%)$, protozoa from the family Trichomonadida was found in guinea pigs (9\%), Eimeria sp. in rabbits (13.9\%), Acanthocephala in primates (15.7\%), and eggs from the generaOxyurida (59\%), along with protozoa from the family Trichomonadida, in reptiles. Capillaria sp. was most prevalent in hedgehogs (33.4\%). Acanthocephala eggs, as well as protozoa from the Giardia and Entamoeba genera, were more frequently found in primates. Parasites common to animals and humans, which may become a source of infection for the latter under certain conditions, have been identified in pet animals.

Keywords: pets; intestinal parasites; helminths; protozoa; prevalence of infection, Moscow; Russia

\section{Introduction}

Moscow is home to a huge number of pet animals, and most of them are cats and dogs. Ferrets, guinea pigs, chinchillas, and rabbits are also often kept in urban apartments. The number of owners who keep hedgehogs, rats, reptiles, and birds is smaller. Small animal enclosures in large shopping malls that often hold squirrels and primates have recently become very popular. Also popular are petting zoos with guinea pigs, rabbits, and mini pigs. Animals have become integral to the life of people living in major metropolitan areas. In most cases, they are full-fledged family members.
Constant veterinary supervision of animal health status, various kinds of preventative activities conducted on a constant basis, the owner's knowledge of animal diseases and their regular visiting city's veterinary clinics contribute to the reduction of some infectious diseases of the animals in the city and improve their quality of life in the event of chronic conditions. Without a doubt, however, certain diseases continue to be a matter of urgency despite the preventative measures that are being taken in a regular manner. Intestinal parasitic diseases caused by various species of helminths and protozoa represent a special case among these pet animal diseases. For this group of diseases, urban areas are an unique

\footnotetext{
$\overline{\text { * }- \text { corresponding author }}$
} 
Table 1. Indices of infection prevalence (IP) for parasitic diseases in pet dogs.

\begin{tabular}{|c|c|c|c|c|c|c|c|}
\hline \multirow{2}{*}{$\begin{array}{l}\text { Types of Parasites } \\
\text { Indices of Infection } \\
\text { Prevalence }\end{array}$} & \multicolumn{6}{|c|}{ Indices of Infection Prevalence } & \multirow{2}{*}{$\begin{array}{c}\text { Total } \\
\text { infected (samples) } \\
(\mathrm{IP}, \%)\end{array}$} \\
\hline & $\begin{array}{c}2012 \\
(I P, \%)\end{array}$ & $\begin{array}{c}2013 \\
(I P, \%)\end{array}$ & $\begin{array}{c}2014 \\
(I P, \%)\end{array}$ & $\begin{array}{c}2015 \\
(I P, \%)\end{array}$ & $\begin{array}{c}2016 \\
(I P, \%)\end{array}$ & $\begin{array}{c}2017 \\
(I P, \%)\end{array}$ & \\
\hline \multicolumn{8}{|l|}{ Helminths } \\
\hline T. canis & $12(4)$ & $5(1.8)$ & $6(2.3)$ & $3(0.98)$ & $6(2.3)$ & $11(2.7)$ & $43(2.4)$ \\
\hline T. leonina & $3(1)$ & $2(0.75)$ & $1(0.38)$ & - & - & $2(0.49)$ & $8(0.45)$ \\
\hline Ancylostomidae & $2(0.67)$ & $1(0.37)$ & $1(0.38)$ & $4(1.3)$ & $1(0.38)$ & $1(0.24)$ & $10(0.57)$ \\
\hline Ancylostoma caninum & - & - & - & - & $1(0.38)$ & - & $1(0.05)$ \\
\hline T. vulpis & - & $3(1.1)$ & $1(0.38)$ & $1(0.32)$ & - & - & $5(0.28)$ \\
\hline Larvae Strongyloides sp. & $1(0.3)$ & - & $1(0.38)$ & $1(0.32)$ & $3(1.1)$ & $10(2.4)$ & $16(0.91)$ \\
\hline Capillaria sp. & $1(0.3)$ & $1(0.37)$ & - & $1(0.32)$ & - & - & $3(0.17)$ \\
\hline Taenia sp. & - & - & $3(1.1)$ & - & $1(0.38)$ & - & $4(0.22)$ \\
\hline S. lupi & - & $1(0.37)$ & - & - & - & - & $1(0.05)$ \\
\hline Examined samples, total & 295 & 266 & 259 & 305 & 260 & 403 & 1752 \\
\hline Samples infected with helminths & 19 & 12 & 12 & 10 & 11 & 24 & 88 \\
\hline Prevalence of infection (\%) & 6.4 & 4.5 & 4.6 & 3.2 & 4.2 & 5.9 & 5 \\
\hline \multicolumn{8}{|l|}{ Protozoa } \\
\hline Giardia sp. & $23(7.7)$ & $21(7.8)$ & $24(9.2)$ & $23(7.5)$ & $21(8)$ & $60(14.8)$ & $172(9.8)$ \\
\hline Sarcocystis sp. & $20(6.7)$ & $28(10.8)$ & $21(8.1)$ & $6(1.9)$ & $14(5.3)$ & $21(5.2)$ & $110(6.2)$ \\
\hline Cystoisospora sp. & $7(2.3)$ & $6(2.2)$ & $9(3.4)$ & $1(0.3)$ & $4(1.5)$ & $9(2.2)$ & $36(2)$ \\
\hline C.canis & $4(1.3)$ & $1(0.37)$ & $3(1.1)$ & $4(1.3)$ & $2(0.76)$ & $3(0.7)$ & $17(0.97)$ \\
\hline Cryptosporidium sp. & $1(0.33)$ & $7(2.6)$ & $4(1.5)$ & $2(0.6)$ & - & $4(0.24)$ & $18(1)$ \\
\hline N. caninum or H. heydorni & - & $2(0.75)$ & $2(0.77)$ & $1(0.3)$ & $1(0.38)$ & $1(0.24)$ & $6(0.34)$ \\
\hline Trichomonadidae & $1(0.33)$ & - & - & - & - & $3(0.7)$ & $4(0.22)$ \\
\hline Samples infected with protozoa & 56 & 65 & 63 & 37 & 42 & 101 & 364 \\
\hline Prevalence of infection (\%) & 18.9 & 24.4 & 24.3 & 12.1 & 16.1 & 25 & 20.7 \\
\hline
\end{tabular}

environment that creates preconditions for circulating pet animal's infections due to widespread importation of animals from other countries and introduction of previously unseen parasite types (Kurnosova, 2009). The high concentration of pet dogs, presence of stray animals, use of common walking areas, and inadequate feces collection within city limits tend to maintain and transmit the source of infection to other animals (Erofeeva \& Doronina, 2017). Many parasitic diseases, especially helminthiases, are low-key infections that are subclinical. In such cases, pet animals become a source of infection for an extended period of time. The course and duration of the desease depends on many factors, such as the type and intensity level of the infestation, the age and immune system status of the animal, and the presence of any concomitant underlying diseases. In general, intestinal parasitic diseases can seriously harm the health of the animal (Kurnosova, 2009; Panova, 2011; Stepanov, 2014).

There are parasitic diseases common to animals and humans that pose a serious threat to the latter (toxocarosis, alveolar echinococcosis, cystic echinococcosis, and toxoplasmosis) (Malysheva et al., 2013; Shcheveleva et al., 2016). Due to the biological features of some parasitic diseases, the risk of direct infection from infected animal to human is very low, because some helminth or protozoan

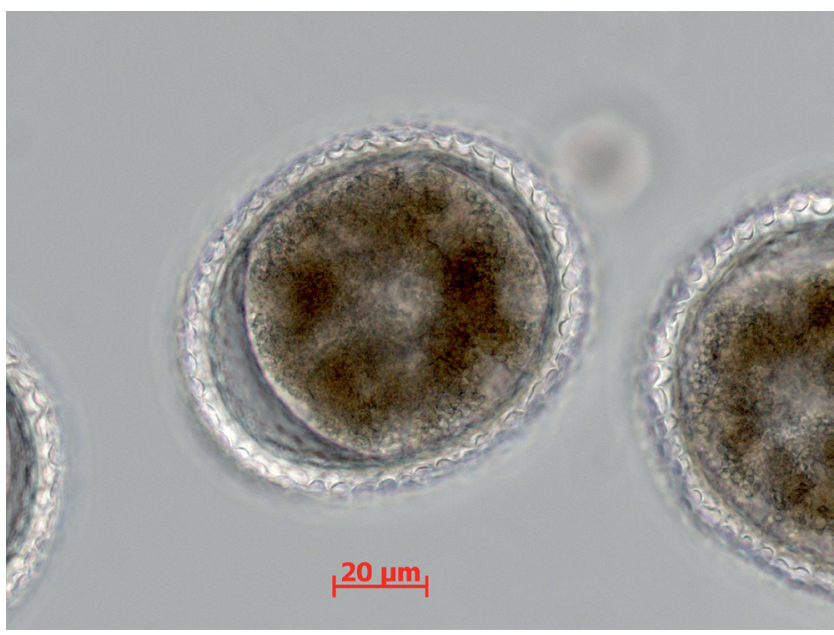

Fig.1. Eggs of Toxocara canis in dog. 
Table 2. Indices infection of prevalence (IP) for parasitic diseases in pet cats.

\begin{tabular}{|c|c|c|c|c|c|c|c|}
\hline \multirow{2}{*}{$\begin{array}{c}\text { Species } \\
\text { of Parasites }\end{array}$} & \multicolumn{6}{|c|}{ Indices of Infection Prevalence } & \multirow{2}{*}{$\begin{array}{c}\text { Total } \\
\text { infected(samples), } \\
(\mathrm{IP}, \%)\end{array}$} \\
\hline & $\begin{array}{c}2012 \\
(I P, \%)\end{array}$ & $\begin{array}{c}2013 \\
(I P, \%)\end{array}$ & $\begin{array}{c}2014 \\
(I P, \%)\end{array}$ & $\begin{array}{c}2015 \\
(I P, \%)\end{array}$ & $\begin{array}{c}2016 \\
(I P, \%)\end{array}$ & $\begin{array}{c}2017 \\
(I P, \%)\end{array}$ & \\
\hline \multicolumn{8}{|l|}{ Helminths } \\
\hline T. cati & $13(6.2)$ & $8(4.2)$ & $11(5.9)$ & $9(4.3)$ & $11(5.8)$ & $21(7.3)$ & $73(5.7)$ \\
\hline T. leonina & $1(0.47)$ & - & - & - & - & - & $1(0.07)$ \\
\hline D. caninum & $3(1.4)$ & $5(2.6)$ & $4(2.1)$ & $2(0.96)$ & $1(0.5)$ & $1(0.35)$ & $16(1.2)$ \\
\hline Taenia sp. & - & $3(1.5)$ & - & $4(1.9)$ & $1(0.5)$ & $2(0.7)$ & $10(0.79)$ \\
\hline Capillaria sp. & - & $1(0.5)$ & - & $1(0.48)$ & $4(2.1)$ & $1(0.35)$ & $7(0.5)$ \\
\hline Ancylostomatidae & - & $2(1)$ & - & - & - & - & $2(0.15)$ \\
\hline Examined samples, total & 209 & 188 & 184 & 207 & 189 & 284 & 1261 \\
\hline Samples infected with helminths & 17 & 18 & 15 & 16 & 17 & 25 & 109 \\
\hline Prevalence of infection (\%) & 1.34 & 1.4 & 1.18 & 1.26 & 1.34 & 1.9 & 8.6 \\
\hline \multicolumn{8}{|l|}{ Protozoa } \\
\hline Giardia sp. & $8(3.8)$ & $7(3.7)$ & $7(3.8)$ & $12(5.7)$ & $11(5.8)$ & $14(4.9)$ & $59(4.6)$ \\
\hline Sarcocystis sp. & $1(0.47)$ & - & $5(2.7)$ & $1(0.48)$ & $1(0.52)$ & $1(0.35)$ & $9(0.71)$ \\
\hline C. rivolta & $2(0.95)$ & $1(0.5)$ & $2(1)$ & $1(2.8)$ & $2(1)$ & $3(1)$ & $11(0.87)$ \\
\hline C. felis & $5(2.3)$ & $6(3.1)$ & $4(2.1)$ & $6(0.48)$ & $8(4.2)$ & $3(1)$ & $32(2.5)$ \\
\hline Cryptosporidium sp. & $4(1.9)$ & $4(2.1)$ & $1(0.5)$ & $5(2.4)$ & $1(0.52)$ & - & $15(1.1)$ \\
\hline Trichomonadidae & $3(1.4)$ & $2(1)$ & $7(3.8)$ & $2(0.96)$ & $8(4.2)$ & $8(2.8)$ & $30(2.3)$ \\
\hline Samples infected with protozoa & 23 & 20 & 26 & 27 & 31 & 29 & 156 \\
\hline Prevalence of infection (\%) & 1.8 & 1.58 & 2 & 2.1 & 2.4 & 2.2 & 12.3 \\
\hline
\end{tabular}

types need a certain environment residence time, temperature, introduced into the environment while already primed for infestaand humidity to be able to infect. There is, however, a group of tion and can be transmitted to humans under certain conditions so-called "contact" parasitic diseases whose infecting principle is (dwarf tapeworms, enterobiasis, giardiosis, cryptosporidiosis,

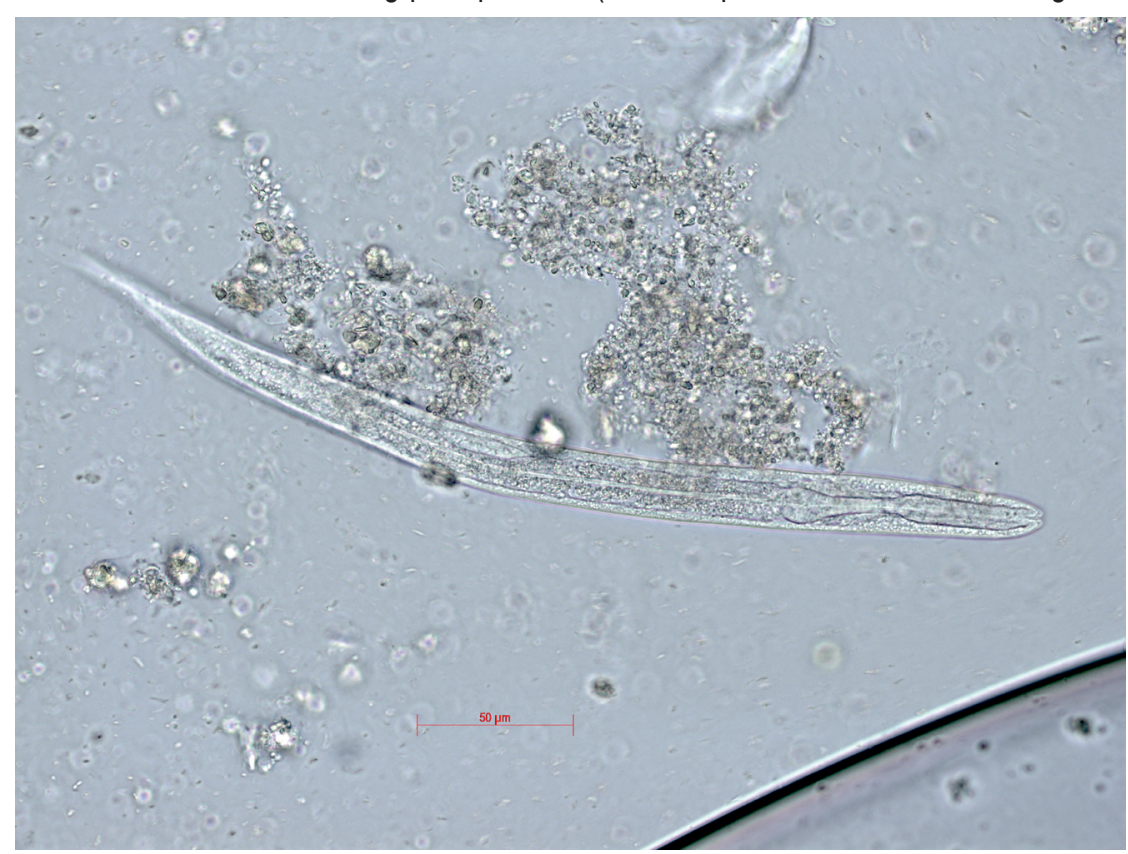

Fig.2. Larva of Strongyloides sp. in dog, stage L1. 


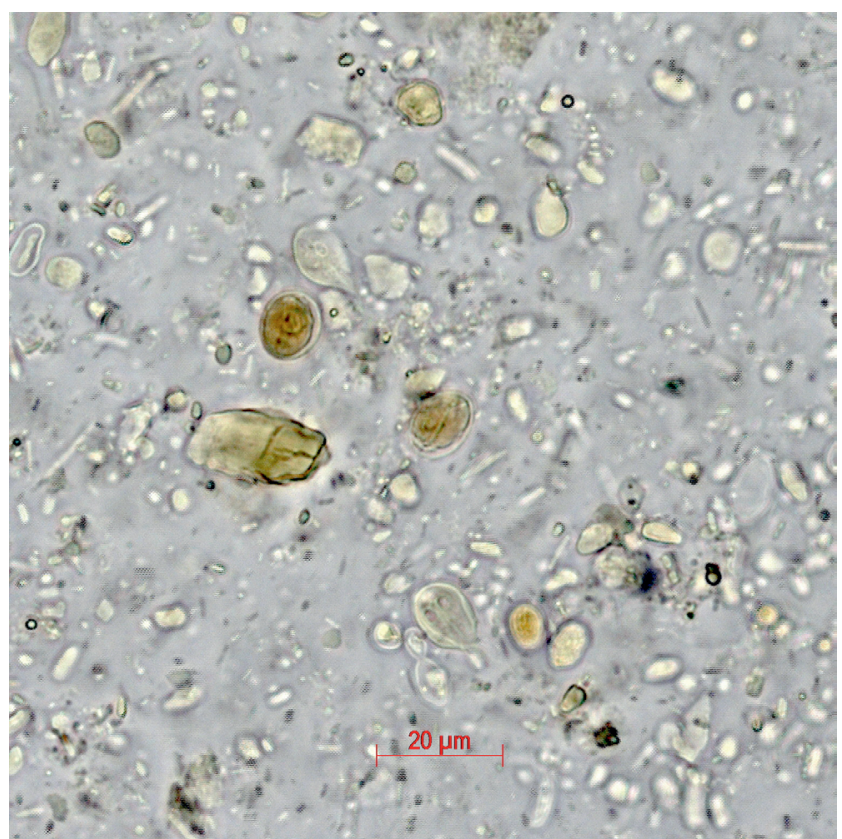

Fig.3. Trophozoites and cysts of Giardia sp. in cat.

blastocystosis, many species of amoebas) (Sergiev et al., 2006). If personal hygiene is inadequate, shelter staff, pet owners, and young children are at risk.

Many major cities are regularly screening pet animals and stray animals for parasitic diseases: St.Petersburg (Prozorov, 1999); Novosibirsk (Zubareva, 2001, Konyaev \& Borcova, 2015); Kostroma (Mikhina, 2008); Moscow (Kurnosova, 2009; Panova, 2011; Uspensky et al., 2011; Loshchinin et al., 2015; Kurnosova \& Odoyevskaya, 2017); London (Upjonh \& Cobb, 2010); Italy, Netherlands, United Kingdon (Feng \& Xiao, 2011), Calgary (Joffe \& Van Niekerk, 2011); Austria, France, Italy, Portugal (Beugnet \& Bourdeau, 2014; Banerh \& Thamsbord, 2016; Pereira \& Martins, 2016). Studies of this type are of particular value if the duration of observation is sufficiently long. In addition to identifying the species composition of the pet animal parasites circulating throughout the city, such a study makes it possible to register new species, take timely remedial and preventative measures, and predict new developments related to the most widespread infections. This publication provides observational data obtained in a 6-year study of disease prevalence in pets in the City of Moscow.

\section{Materials and Methods}

The study was conducted at the Veterinary Laboratory "Pasteur". Animal fecal samples were delivered to the laboratory in special plastic containers or glassware.

Feces obtained from various animal species were studied using a variety of methods including flotation with sodium chloride and ammonium nitrate solutions. Some flotation and sedimentation techniques are used only in Russia. For instance, Kotelnikov-Varenichev's and Kotelnikov-Chrenov's methods are centrifugal flotation techniques, which have high sensitivity for many helminth species (Kotelnikov, 1974; Kotelnikov \& Chrenov 1980), ether and formalin precipitation, and direct smear microscopy (MUC 4.2.3145-13). Sometimes all the research methods were used simultaneously based on the particular features of the approach used to identify various species of protozoa, in accordance with the nature of the fecal sample under test.

Microscopy was performed at 10x and 40x magnification using a Lomo microscope (Joint stock company Lomo, Russia). The species of helminth eggs and protozoan cysts were determined based on their morphological features and size.

After examination, the material samples were disinfected by autoclaving.

\section{Ethical Approval}

The animal study was in compliance with all the 209 relevant national regulations and institutional policies relating to the care and use of animals in Russia.

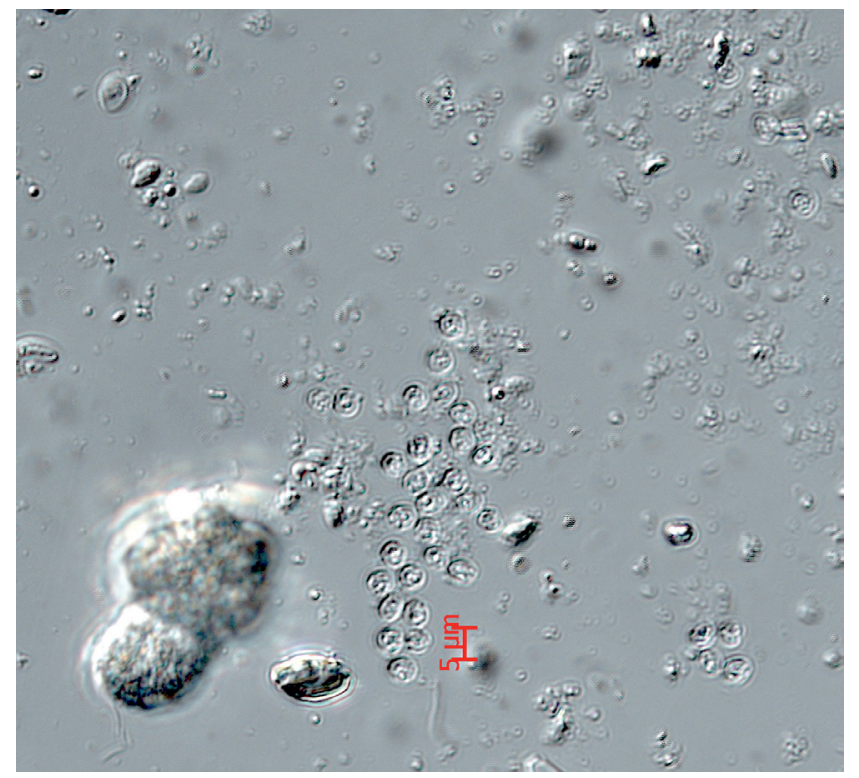

Fig.4.Oocysts of Cryptosporidium sp. in ferret.

\section{Results}

The pet animal study was conducted for 6 years from 2012 to 2017. During this period, we studied fecal samples from 1752 dogs (Canis lupus), 1261 cats (Felis catus), 323 ferrets (Mustela putorius), 217 chinchillas (Chinchilla lanigera), 132 guinea pigs (Cavia porallus), 165 rabbits (Oryctolagus cuniculus), 65 tamarins (Saguinus oedipus), 50 marmoset (Callithrix jacchus), 10 galago (Galago senegalensis), 10 chimpanzee (Pan troglodytes), 10 turtles (Testudo horsfieldii), 11 geckos (Gekkonidae), 21 hedgehogs (Erinaseus europaeus).

In the dogs, we discovered eight different helminths and seven dif- 
ferent protozoa, i.e. Toxocara canis, Toxascaris leonina, Trichuris vulpis, Ancylostomatidae , Ancylostoma caninum, Spirocerca lupi, Taenia sp., Capillaria sp.; Sarcocystis sp., Cystoisospora canis, Cystoisospora sp., Giardia sp., Neospora caninum and/or Hammondia heydorni, Thrichomonadidae, and Cryptosporidium sp. (Table 1).

T.canis eggs were found in 43 samples ( $2.4 \%$ infection prevalence $(\mathrm{IP})$ is the percentage of a infected animals in the total population) (Fig. 1)., T.leonina eggs in 8 samples $(0.4 \% \mathrm{IP})$, Strongyloides sp. larvae in 16 cases $(0.9 \%$ IP) (Fig. 2), Trichuris vulpis in 5 samples $(0.28 \% \mathrm{IP})$, S.lupi in 1 sample $(0.05 \% \mathrm{IP})$, Taenia sp. in 4 cases $(0.2 \% \mathrm{IP})$, Ancylostomatidae in 10 cases $(0.5 \% \mathrm{IP})$, A.caninum in one case $(0.05 \% \mathrm{IP})$, and Capillaria sp. in 3 cases $(0.17 \%$ IP). Intestinal protozoa including Giardia sp. were identified in 172 cases (9.8 \% IP), Sarcocystis sp. in 110 cases (6.2\% IP), Cystoisospora sp. in 36 cases (2 \% IP), C.canis in 17 cases (0.9\% IP), Cryptosporidium sp. in 18 cases (1 \% IP), N.caninum or/and H.heydorni in 6 cases $(0.34 \% \mathrm{IP})$, and Thrichomonadidae in 4 cases $(0.2 \% \mathrm{IP})$.

In the case of mixed infections are most frequently caused by a

Table 3. Indices of prevalence of infection (IP) by intestinal parasites in other house-kept animals.

\begin{tabular}{|c|c|c|c|c|c|c|c|}
\hline \multirow{2}{*}{$\begin{array}{l}\text { Animal species; } \\
\text { Type of infestation }\end{array}$} & \multicolumn{6}{|c|}{ Indices of Infection (IP, \%) } & \multirow[b]{2}{*}{ Total Infected (IP, \%) } \\
\hline & 2012 & 2013 & 2014 & 2015 & 2016 & 2017 & \\
\hline \multicolumn{8}{|l|}{ Ferrets } \\
\hline Capillaria sp. & $1(2.8)$ & - & - & - & - & - & $1(0.3)$ \\
\hline Cryptosporidium sp. & $2(5.7)$ & $7(14.2)$ & $5(9.2)$ & $5(8.6)$ & $1(1.8)$ & $1(1.3)$ & $21(6.5)$ \\
\hline Eimeria sp. & $1(2.8)$ & $1(2)$ & $2(3.7)$ & $3(5.1)$ & $8(15)$ & $2(2.7)$ & $17(5.2)$ \\
\hline Giardia sp. & - & $1(2)$ & - & $2(3.4)$ & - & $2(2.7)$ & $5(1.5)$ \\
\hline Total Examined & 35 & 49 & 54 & 58 & 53 & 74 & 323 \\
\hline Of them, infected & 4 & 9 & 7 & 10 & 9 & 5 & 41 \\
\hline $\mathrm{IP}, \%$ & 11.4 & 18.3 & 12.9 & 17.2 & 16.9 & 6.7 & 12.6 \\
\hline \multicolumn{8}{|l|}{ Chinchillas } \\
\hline Giardia sp. & $6(33.3)$ & $9(45)$ & $35(48.6)$ & $24(46.1)$ & $9(36)$ & $20(50)$ & $103(47.4)$ \\
\hline H.nana & $1(5.5)$ & - & - & - & - & - & $1(0.46)$ \\
\hline Blastocystis sp. & - & - & - & $1(1.9)$ & - & - & $1(0.46)$ \\
\hline Entamoeba sp. & - & - & $1(1.3)$ & $1(1.9)$ & - & - & $2(0.92)$ \\
\hline Trichomonas sp. & $1(5.5)$ & $2(10)$ & - & $1(1.9)$ & - & - & $4(1.84)$ \\
\hline Total Examined & 18 & 20 & 72 & 52 & 25 & 40 & 217 \\
\hline Of them, infected & 8 & 11 & 36 & 27 & 9 & 20 & 111 \\
\hline $\mathrm{IP}, \%$ & 44.4 & 55 & 50 & 51.9 & 36 & 50 & 51.1 \\
\hline \multicolumn{8}{|l|}{ Guinea Pigs } \\
\hline Trichomonas sp. & $1(4.7)$ & $5(12.8)$ & $4(30)$ & $1(7.1)$ & - & $1(4)$ & $12(9)$ \\
\hline Giardia sp. & - & $1(2.5)$ & - & - & $1(5)$ & $3(12)$ & $5(3.7)$ \\
\hline Entamoeba sp. & - & $3(7.6)$ & $1(7.6)$ & $1(7.1)$ & - & - & $5(3.7)$ \\
\hline Total Examined & 21 & 39 & 13 & 14 & 20 & 25 & 132 \\
\hline Of them, infected & 1 & 9 & 5 & 2 & 1 & 4 & 22 \\
\hline $\mathrm{IP}, \%$ & 4.7 & 23 & 38.1 & 14.1 & 5 & 16 & 16.6 \\
\hline \multicolumn{8}{|l|}{ Rabbits } \\
\hline P.ambiguis & - & - & $2(15.3)$ & - & $2(3.5)$ & - & $4(2.4)$ \\
\hline Giardia sp. & - & - & - & - & $2(3.5)$ & $1(1.3)$ & $3(1.8)$ \\
\hline Eimeria sp. & - & - & - & - & $14(24.5)$ & $9(12.5)$ & $23(13.9)$ \\
\hline Total Examined & 5 & 9 & 13 & 9 & 57 & 72 & 165 \\
\hline Of them, infected & 0 & 0 & 2 & 0 & 18 & 10 & 30 \\
\hline $\mathrm{IP}, \%$ & 0 & 0 & 15.3 & 0 & 31.5 & 13.8 & 18.1 \\
\hline
\end{tabular}


Primates (tamarins, marmosats, saimiri,galago, capuchins, chimpanzee)

\begin{tabular}{|c|c|c|c|c|c|c|c|}
\hline Acanthocephala & - & $13(27)$ & $5(55.5)$ & - & - & $4(7)$ & $22(15.7)$ \\
\hline Streptapharagus sp. & - & $2(4.1)$ & $1(11.1)$ & $1(7.1)$ & - & - & $4(2.8)$ \\
\hline Blastocystis sp. & - & $2(4.1)$ & - & $1(7.1)$ & - & - & $3(2.1)$ \\
\hline Entamoeba sp.. & - & $4(8.3)$ & - & $1(7.1)$ & - & - & $5(3.5)$ \\
\hline Trichomonas sp. & - & $1(2)$ & - & - & $1(8.3)$ & $2(3.5)$ & $4(2.8)$ \\
\hline Giardia sp. & - & - & - & - & $4(33.3)$ & $1(1.7)$ & $5(3.5)$ \\
\hline Total Examined & 0 & 48 & 9 & 14 & 12 & 57 & 140 \\
\hline Of them, infected & 0 & 22 & 6 & 3 & 5 & 7 & 43 \\
\hline $\mathrm{IP}, \%$ & 0 & 45.8 & 66.6 & 21.4 & 41.6 & 12.2 & 30.7 \\
\hline \multicolumn{8}{|c|}{ Reptiles (turtles, geckos) } \\
\hline Oxyurida & - & - & - & $1(0.48)$ & $1(0.48)$ & $12(0.48)$ & $13(59)$ \\
\hline Blastocystis sp. & 1 & -- & - & - & $1(0.48)$ & $2(0.48)$ & $4(18.1)$ \\
\hline Entamoeba sp. & $1(0.48)$ & - & - & - & - & $1(0.48)$ & $2(9.5)$ \\
\hline Trichomonas sp. & - & - & - & - & $1(0.48)$ & $6(0.48)$ & $7(33.3)$ \\
\hline Isospora sp. & - & - & - & - & - & $3(0.48)$ & $3(14.2)$ \\
\hline Total Examined & 1 & 0 & 1 & 4 & 0 & 15 & 22 \\
\hline Of them, infested & 1 & 0 & & 1 & 0 & 15 & 18 \\
\hline $\mathrm{IP}, \%$ & 100 & 0 & 0 & 25 & 0 & 100 & 81.8 \\
\hline \multicolumn{8}{|l|}{ Hedgehogs } \\
\hline Capillaria sp. & - & - & - & - & & $7(0.48)$ & $7(33.4)$ \\
\hline C. striatum & & & & - & & $2(0.48)$ & $2(9.5)$ \\
\hline Total Examined & 1 & - & 1 & 4 & 0 & 15 & 21 \\
\hline Of them, infected & 0 & & 0 & 0 & 0 & 9 & 9 \\
\hline $\mathrm{IP}, \%$ & 0 & & 0 & 0 & 0 & 60 & 42.8 \\
\hline
\end{tabular}

combination of two species of protozoa, less frequently by a combination of one type of helminths and one type of protozoa. A total of 59 cases of mixed infections in dogs were detected (Table 4). It was determined that young animals (younger than one year of age) had the highest level of intestinal parasite infection in dogs. Thus, the prevalence of toxocarosis in puppies, based on the total number of positive samples (43 samples were positive, with 31 of them obtained from puppies) was $72 \%$. The incidence was $62.2 \%$ for Giardia sp., $76.4 \%$ for C. canis, $69.4 \%$ for Cystoisospora sp., and $55.5 \%$ for Cryptosporidium sp. The frequency of detection for Sarcocystis sp. was $36.3 \%$.

In the pet cats, we identified the following 6 species of helminths: T. cati, T. leonina, Capillaria sp., Dipylidium caninum, Ancylostomatidae, Taenia sp. and 6 species of intestinal protozoa: Giardia sp., Cystoisospora rivolta, Cystoisospora felis, Sarcocystis sp., Thrichomonadidae, and Cryptosporidium sp.( Table 2)

The most common helminthiasis in cats was toxocarosis, with T. cati eggs found in 73 samples (5.7\% infection prevalence (IP )), proglottids of D.caninum in 16 samples (1.2\% IP), Taenia sp. eggs in 10 samples $(0.7 \%$ IP), Capillaria sp. in 7 samples $(0.5 \%$
IP), T.leonina in $1(0.07 \% \mathrm{IP})$, and Ancylostomatidae in 2 samples $(0.15 \% \mathrm{IP})$.

The most common feline protozoan disease was Giardia sp., which was found in 59 samples (4.6\% IP) (fig 3). C. felis was found in 32 samples $(2.5 \% \mathrm{IP})$, C. rivolta in 11 samples $(0.8 \% \mathrm{IP})$,

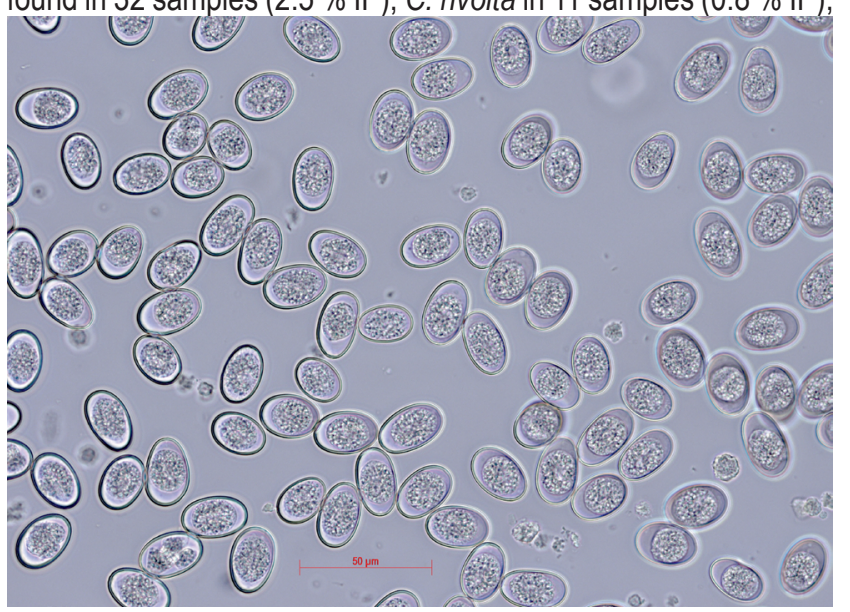

Fig.5. Oocysts of Eimeria sp. in ferret. 


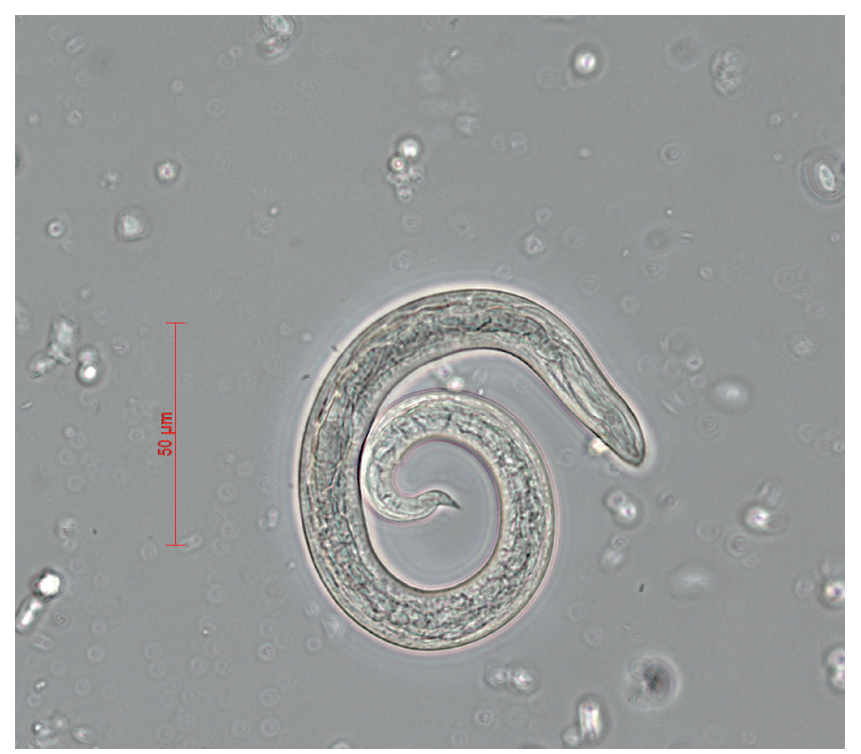

Fig.6. Larva of Crenosoma striatum in hedgehog, stage L1.

Sarcocystis sp. in 9 samples $(0.7 \%$ IP), Cryptosporidium sp. in 15 samples $(1.1 \% \mathrm{IP})$, and Thrichomonadidae in 30 samples $(2.3 \% \mathrm{IP})$.

There were 26 cases of mixed infections in the cats, most of them were caused by two species of parasites, with only one case involving a combination of 4 species of parasites (Table 4).

In the ferrets, we found a single type of helminths belonging to the genus Capillaria ( $0.3 \%$ infection prevalence (IP) and 3 species of protozoa, i.e. Cryptosporidium sp., Giardia sp., and Eimeria sp. (Table 3). The most frequently seen parasites were Cryptosporidium sp., found in 21 cases (6.5 \% IP) (Fig. 4), and Eimeria sp., found in 17 cases (5.2 \% IP) (Fig.5), with Giardia sp. cysts represented to a lesser extent. Only one case involving one type of helminths, i.e. H.nana, was identified in the chinchillas along with 4 species of protozoa: Giardia sp., Blastocystis sp., Entamoeba sp., and Trichomonas sp. The most common intestinal protozoa in the chinchillas were Giardia sp. with 193 cases and an IP value of $47.7 \%$. There were 4 cases of Trichomonas sp. (1.8\% IP) and isolated instances of other species $(0.4 \% \mathrm{IP})$. The only intestinal parasites found in the guinea pigs were protozoa represented by three species, i.e. Entamoeba sp., Trichomonas sp., and Giardia $\mathrm{sp}$., with the most frequently seen protozoa being Trichomonas sp. with 12 cases ( $9 \%$ IP) and cysts of Giardia sp. and amoebas (3.7 \% IP). One species of helminths, i.e. Passalurus ambiguus with an IP of $2.4 \%, 2$ species of Eimeria sp. with 23 cases (13.9\% $\mathrm{IP})$, and Giardia sp. with 3 cases (1.8\% IP), which were encountered much less frequently, were identified in the rabbits. The primates (data for all types) were shown to be $15.8 \%$ infected with Acanthocephala. The stomach nematodes of the Streptopharagus sp. are seen much less frequently: $2.8 \%$. Intestinal protozoa were represented by 4 species: Giardia sp. (3.5\% IP), Blastocystis sp. (2.1\% IP), Entamoeba sp. (3.5\% IP), and Trichomonas sp. (2.8\% IP). One species of helminths of the genera Oxyurida was identi- fied in four cases in the reptiles along with 4 species of protozoa: Blastocystis sp. (18.1\% IP), Entamoeba sp. (9.5 \% IP), Trichomonas sp. $(33.3 \% \mathrm{IP})$ and Isospora sp. $(14.5 \% \mathrm{IP})$. Only two species of helminths were identified in the hedgehogs, i.e. Capillaria $\mathrm{sp}$. in 7 cases $(33.4 \% \mathrm{IP})$ and Crenosoma striatum in 2 cases $(9.5 \%$ IP) (Fig. 6).

In certain isolated cases, feces from lemurs (Lemur catta) containing helminths of the Enterobius sp. (data not listed in the tables) were submitted for examination along with feces from meerkats (Suricata suricatta), raccoons (Procyon lotor), degu (Octodon degus), and echidna (Tachyglossidae), in which no intestinal parasites were identified. Protozoa from the Eimeria sp., eggs of Catenotaeniidae and eggs of the genera Oxyurida were found in squirrels (Sciurus vulgaris).

\section{Discussion}

The study has shown that Toxocara spp. are the most widespread parasites in dogs and cats. Different researchers give different IP values, which may be dependent on the category of the animals under study (examination of all animals in veterinary clinics, animals in shelters, stray animals) (Kurnosova \& Odoyevskaya, 2017). It is quite common for Toxocara spp. infections to rank first in terms of prevalence in dogs and cats in an urban environment. In addition, cats have a higher level of infection with Toxocara sp. than dogs. Currently the role of cats in the epidemiology of human toxocariasis remains unclear and it may be true that the latter are a source of infection for humans to a greater extent than previously thought (Fogt-Wyrwaset et al., 2007; Espinoza et al., 2010; Panova, 2011). The results of our study are in agreement with other authors (Prozorov, 1999; Zubareva, 2001; Mikhina, 2008; Kurnosova, 2009; Panova, 2011; Kurnosova \& Odoyevskaya, 2017;). In this situation, the urban environment favors the spread of toxocarosis infection, in which the main factor of accumulation and spread is the ground of the pet walking areas and the permanent habitat of stray dogs and cats. These conditions ensure constant circulation of this species of helminths, which is fraught with constant re-infection and infection of additional animals. The rest of the helminth species are found less frequently, which is due to the conditions of indirect transmission of a particular species involving intermediate and/or additional hosts. In such a case, cats and dogs get infected when they go away from the city for the summer. In recent years, larvae of Strongyloides sp. have been found more frequently than before (Umur \& Meral, 2017; Paradies \& larussi, 2017). This nematode species is found not only in dogs going away from the city or country, but also in animals residing within city limits at all times, mostly in puppies kept in breeding kennels. The Laboratory received material from animals suffering from long-term infection. The course of this type of infection is severe in young animals and disrupts the normal functioning of the gastrointestinal tract, which is manifested in a loss of appetite, copious mucus-laden stools, or intractable diarrheas (Umur \&Meral, 2017). 
Table 4. Combination mixed infections in dogs and cats.

\begin{tabular}{|c|c|c|}
\hline Mixed infections & $\begin{array}{c}\text { Species of } \\
\text { animals }\end{array}$ & $\begin{array}{l}\text { Number of } \\
\text { combinations }\end{array}$ \\
\hline Sarcocystis sp. and Giardia sp. & $\operatorname{dog}$ & 7 \\
\hline Cystoisospora sp. and Giardia sp. & dog & 6 \\
\hline Cystoisospora sp. and C. canis & dog & 4 \\
\hline N. caninum and/or H. heydorni and Sarcocystis sp. & dog & 4 \\
\hline T. canis and Giardia sp./ and Sarcocystis sp. & $\operatorname{dog}$ & $3 / 3$ \\
\hline T. canis and Cystoisospora sp./ and Cryptosporidium sp. & dog & $2 / 2$ \\
\hline larvae of Strongyloides sp. and C. canis/and Giardia sp. & dog & $2 / 2$ \\
\hline Giardia sp. and Cryptosporidium sp./and C. canis & dog & $2 / 2$ \\
\hline Sarcocystis sp. and Cystoisospora sp. & dog & 2 \\
\hline larvae of Strongyloides sp. and Thrichomonadidae /and Cystoisospora sp. & dog & $1 / 1$ \\
\hline Ancylostomatidae and Sarcocystis sp. /and Giardia sp./and C. canis/and Capillaria sp. & $\operatorname{dog}$ & $1 / 1 / 1 / 1$ \\
\hline T. canis and Trichuris vulpis & $\operatorname{dog}$ & 1 \\
\hline T. leonina and Giardia sp. & dog & 1 \\
\hline \multirow{2}{*}{ Giardia sp. and Thrichomonadidae } & dog & 1 \\
\hline & cat & 9 \\
\hline Sarcocystis sp. and C. canis & dog & 1 \\
\hline Sarcocystis sp. and Cryptosporidium sp. & dog & 1 \\
\hline T. canis, C. canis, and Cryptosporidium sp.; & $\operatorname{dog}$ & 1 \\
\hline T.leonina, Cryptosporidium sp., and Thrichomonadidae; & dog & 1 \\
\hline Strongyloides sp., Giardia sp., and Cystoisospora sp. & dog & 1 \\
\hline Sarcocystis sp., Giardia sp., and Cryptosporidium sp.; & $\operatorname{dog}$ & 1 \\
\hline Sarcocystis sp., Giardia sp . and Cystoisospora sp. & dog & 1 \\
\hline Sarcocystis sp., N. caninum and/or H. heudorni and Giardia sp. & dog & 1 \\
\hline T. canis, T. leonina, Giardia sp., and C. canis & dog & 1 \\
\hline T. cati and C. felis & cat & 3 \\
\hline T. cati and Capillaria sp./ and Giardia sp. & cat & $2 / 1$ \\
\hline Giardia sp. and C. rivolta & cat & 2 \\
\hline T. leonina and Giardia sp. & cat & 1 \\
\hline Ancylostomatidae and Cryptosporidium sp. & cat & 1 \\
\hline T. cati and C. rivoltal and Sarcocystis sp. & cat & $1 / 1$ \\
\hline C. felis and Cryptosporidium sp./ and Giardia sp./ and C. rivolta & cat & $1 / 1 / 1$ \\
\hline Sarcocystis sp. and Thrichomonadidae & cat & 1 \\
\hline Ancylostomatidae, T. cati, Taenia sp. and Cryptosporidium sp. & cat & 1 \\
\hline
\end{tabular}

Giardiosis ranks first in terms of prevalence among the protozoan diseases of dogs, cats, and chinchillas, with puppies younger than 1 year of age affected most frequently in the case of dogs (Upjonh \& Cobb, 2010; Kurnosova, 2014). At the same time, in cats and chinchillas this species of protozoa is found with equal frequency in young and adult animals. Such prevalence of Giardia spp. is related to their environmental resistance (Adam, 2001). In dogs, Giardia spp. are found more frequently than in cats, which may be due to the animal's daily walking routines and their infection from the environment, as well as to the habit of some dogs to eat the feces of other animals. An animal with weak immunity may become a long-term host to these protozoa. As of now, the role of pet animals in the transmission of this infection to humans within city limits has not been established (Feng \& Xiao, 2011; Thompson \& Monis, 2004; Thompson \& Palmer, 2008; Upjonh \& Cobb, 2010). Sarcocystidae are found in dogs more frequently than in cats, which is due to the fact that cats are more often fed dry kibble. In general, however, the prevalence of Sarcocystidae infection has declined in recent years and they now rank second after giardiosis. Infections by flagellated protozoa from the Thrichomonadidae family have recently started cropping up in cats of various ages. These protozoa are sufficiently pathogenic and difficult to treat. The species of trichomonads circulating among cats within city limits have not been established. The animals suffered from chronic diarrhea whenever trichomonads were found. In dogs and cats, Cryptosporidium sp. and Cystoisospora spp. are less prevalent and are found mostly in young animals( Hamnes \& Gjerde, 2007; Garanayak \& Gupta, 2017). It should be noted that protozoa from the family Sarcocystidae have not been detected in feline fecal samples during the entire study period, which is compatible with the widely expressed view regarding quick and often asymptomatic excretion of cysts into the environment that goes unnoticed by the owners (Greene, 2011). 
In general, and as already shown by previously conducted studies, intestinal protozoa in dogs and cats are found more frequently than helminthosis (Kurnosova, 2009).

Of particular interest is research relating to the group of exotic animals, which are not kept in urban apartments as much as other species. Nevertheless, many species of these animals are gaining in popularity. Monkeys, squirrels, and some species of rodents are normally kept in mini-zoos and large shopping malls in Moscow. They are much less frequently kept by individuals. Owners are increasingly starting to keep rabbits and, less frequently, reptiles and hedgehogs in urban apartments. The research has shown that exotic animals are infected mostly by helminths and protozoa found only in these animal species, although some need to be highlighted their importance in Public Health (Hallinger \& Taubert, 2018). The primates infected with Acanthocephala. This species of helminths is widespread in animals, which is due mostly to the fact that the animals are fed insects acting as intermediate hosts to these helminths. While the protozoa from the Entamoeba sp. that are most frequently found in monkeys, reptiles, and guinea pigs are represented mostly by Endolimax nana and lodamoeba $\mathrm{sp}$., it has not been always possible to determine the species of some amoeba cysts. No dysenteric amoeba (Entamoeba histolytica) cysts capable of transmission to humans have been identified over the entire study period (Regan \& Yon, 2014; Levecke \& Dreesen, 2010; Verweij \& Brienen, 2003). However, in addition to the species-specific parasites, helminths and protozoa of a zoonotic nature (eggs of Hymenolepsis nana, blastocysts) have also been found in this category of animals under study (Cian \& Safadi, 2017). Certainly, when an exotic animal is bought, the animal should be screened for parasitic diseases. In addition, animals leaving city or country limits or those participating in hunting, actively catching and eating insects, rodents, and amphibians may get infected by zoonotic diseases (Hallinger \& Taubert, 2018). The same danger should be kept in mind when brining the younglings of wild animals from the forest.

Thanks to the veterinary and medical awareness-building work by the mass-media and the Internet, pet owners have become sufficiently knowledgeable about many issues relating to animal diseases and various preventative activities. Nevertheless, studies have shown that under urban conditions parasitic diseases are relevant both to veterinary science and to medicine (Stepanov, 2014; Shcheveleva et al., 2016).

Thus, veterinarians and pet owners should take the species of their animal, it's origin, living and feeding conditions into consideration in order to take preventative measures aimed at timely identification of parasitic infections and their correct treatment under veterinary supervision, which will ensure the animal's health and protect the environment from the spread of infections. Studying a wide range of pet animals under urban conditions has great value not only from a practical standpoint, but also in terms of determining the epizootic situation for all the major parasitic diseases in general and clarifying the human risks associated with the zoonotic nature of the parasitic infections.

\section{Conclusion}

The study has shown the widespread circulation of intestinal parasitic infections of house-kept animals in the city of Moscow. The high concentration of animals within confined areas promotes constant circulation of numerous helminths and protozoa among pet animals. Toxocara spp. and Giardia sp.were found more frequently in dogs and cats together with other parasitic agents are a pressing issue both for veterinary science and for medicine. In summary, helminths and protozoa capable of transmission to humans have been identified among a wide range of pet animal infections in an urban environment.

\section{Conflict of Interest}

Authors state no conflict of interest.

\section{References}

Adam, R.D. (2001): Biology of Giardia lamblia. Clin. Microbiol. Rev., 14(3): $447-475$

Erofeeva, V.V., Doronina, G.N. (2017): The threat of spreading helminth eggs in the soil of urban areas. The Young Scientist, 22: 222 - 224 (In Russian)

Espinoza, Y.A., HuapayA, P.E., Roldan, W.H. (2010): Seroprevalence of human toxocariasis in Andean communities from the Northeast of Lima. Rev. Inst. Med. Trop. Sau Paulo, 52: 31 - 36

Baneth, G., Thamsborg, S.M., Otranto, D.O., Guillot, J., Blaga, R., Deplazes, P., Solano-Gallego, L. (2016): Major Parasitic Zoonoses Associated with Dogs and Cats in Europe. J. Comp. Pathol., 155: 54 - 74. DOI: 10.1016/j.jcpa.2015.10.179

Becker, A.C, Kraemer, A, Epe, C., Strube, C. (2016): Sensitivity and efficiency of selected coproscopical methods-sedimentation, combined zinc sulfate sedimentation-flotation, and McMaster method. Parasitol. Res., (113): 2401-2406. DOI: 10.1007/s00436016-5003-8

Beugnet, F., Bourdiau, P., Chalvet-Monfray, R., Cozma, V., Farkas, R., Guillot, J., Halos, L., Joachim, A., Losson, B., Miró, G., Otranto, D., Renaud, V., Rinaldi, L. (2014): Parasites of domestic owned cats in Europe: co-infestations and risk factors. Parasit. Vectors, (7): 291. DOI: 10.1186/1756-3305-7-291

FENG Y, XIAO L. (2011): Zoonotic potential and molecular epidemiology of Giardia species and giardiasis. Clin. Microbiol. Rev., 24(1): 110 - 140. DOI: 10.1128/CMR.00033-10

Fogt-WyrWas, R., Jarosz, W., Mizgajska-Wiktor, H. (2007): Utilizing a polymerase chain reaction method for the detection of Toxocara canis and T. cati eggs in soil. J. Helminthol., 81: 75 - 78. DOI: 10.1017/S0022149X07241872

Greene, C.E. (2011): Infectious diseases of the dog and cat. Print Saunders, $1376 \mathrm{pp}$. 
Grecca M., Thomaz-Soccol V., Costa M., Silvia R., Osaki K. (2013): Occurrence of Cryptosporidium sp. in dogs and cats from curitiba and its metropolitan area. Arch. Vet. Sci., 18(3): $01-06$. DOI:10.5380/avs.v18i3.29522

Hamnes, I., GJeRde, B., Robertson, L. (2007): A longitudinal study on the occurrence of Cryptosporidium and Giardia in dogs during their first year of life. Acta Vet. Scand., 49(1): 22. DOI: 10.1186/17510147-49-22

Joffe, D., Van Niekerk, D., Gagné, F., Gilleard, J., Kutz, S., Lobingl$E R, R .(2011):$ The prevalence of intestinal parasites in dogs and cats in Calgary, Alberta. Can. Vet. J., 52(12): $1323-1328$

KonyaEv, S.V., Borcova, M.S. (2015): Giardiasis (Giardia) of dogs in Russia: the prevalence and effective treatment. RVJ, 5: $42-44$ (In Russian)

KoteLNIKOV, G.A (1974): Diagnostics of animal helminthiasis. Moscow, Koloss, 240 pp. (In Russian)

KotelniKov, G.A, Chrenov, V.M. (1980): Guidelines for Diagnostic Frequency Helminthiasis in Farm Animals. Moscow (In Russian) KuRnosova, O.P. (2014): Distribution of protozoa Lamblia (Giardia) sp. among dogs and cats of Moscow. Med. Parasitol.,(3): $23-25$ (In Russian)

Kurnosova, O.P., Odoyevskaya, I.M. (2017): Toxocariasis in pet dogs and cats. Med. Parasitol., 4: 30 - 34 (In Russian)

Kurnosova, O.P. (2009): Parasitic diseases in domestic dogs and cats in metropolitan Moscow. Med. Parasitol., 4: 31 - 35 (In Russian)

Laboratory diagnosis of helminthiases and protozoosis: MUC 4.2.3145-13, Moscow (In Russian)

Levecke, B., Dreesen, L., Dorny, P., VerweiJ, J., Vercammen, F., Casaert, S., Vercruysse, J., Geldhof, P. ( 2010): Molecular Identification of Entamoeba spp. In Captive Nonhuman Primates. Clin. Vet. Microbiol., (48): 2988-2990. DOI: 10.1128/JCM.00013-10

LOSHCHININ, M.N., StUdenNIKOVA, U.V., BELIMENKO, V.V. (2015): Intestinal protozooses of dogs and cats in urbanized ecosystems. Russian Vet. J., 1: 20 - 21 (in Russian)

Malysheva, N.S., Samofalova, N.A., Grigoriev, D.G., Vagin, N.A., Elizarov, A.S., GladkiKH, K.A., ShuikInA, E.E. (2013): The problem of toxocariasis in the current situation and improvements in approaches to its prevention. Scientific Notes: Electronic scientific journal of the Kursk State University, 1: 25 - 30 (In Russian)

MIKHINA, N.V. (2008): Epizootology, pathomorphology and improvements in the therapy of helminthiases of cats. Author's abstract of a dissertation for the award of the degree of Candidate of Veterinary Sciences, Moscow (In Russian)

PanOva, O.A. (2011): Toxocariasis of carnivorous: diagnostic methods and bioecological aspects of development of pathogens in a metropolis. Authoref. Dis. Cand. Biol. Sci. Moscow (In Russian) Paradies, P., larussi, F., Sasanelli, M., Capogna, A., Lia, R., Zucca, D., Greco, B., Cantacessi, C., Otranto, D. (2017): Occurrence of strongyloidiasis in privately owned and sheltered dogs: clinical presentation and treatment outcome. Parasit. Vectors, (10): 345. DOI: 10.1186/s13071-017-2275-5
Pereira, A. , Martins, A. , Brancal, H. , Vilhena, H., Sillva, P., Pimenta, P., Diz-Lopes, D., Neves, N., Colmbra, M., Alves, F., Cardoso, L., MAIA, K.(2016): Parasitic zoonoses associated with dogs and cats: a survey of Portuguese pet owners' awareness and deworming practices. Parasit. Vectors, 9: 245. DOI: 10.1186/s13071-0161533-2

Prozorov, A.M. (1999): Parasitic diseases of dogs and cats in St. Petersburg. Author's abstract of a dissertation for the award of the degree of Candidate of Biological Sciences, St. Petersburg (In Russian)

Regan, C.S., Yon, L., Hossain, M., ElsheIKHA, M. (2014): Prevalence of Entamoeba species in captive primates in zoological gardens in the UK. PeerJ., (2): 492. DOI: 10.7717/peerj.492

Sergiev, V.P., Lobzin, Yu.V., Kozlov, S.S. (2006): Human parasitic diseases. S. Petersburg, 240 pp. (In Russian)

ShcheVeleva, T.N., Sofyin, V.S., Mironova, N.I., Karakotin, A.A. (2016): The epidemiologic characteristics of toxocariasis (review of literature and own research). Scientific review. Med. Sci., 6: 124 - 128 (In Russian)

Stepanov, V.A. (2014): Improvements in measures against parasitic diseases of carnivorous animals (pharmacological and toxicological properties of new topical drugs). Author's abstract of a dissertation for the award of the degree of Candidate of Veterinary Sciences, Moscow (In Russian)

Thompson, R.C., Monis, P.T. (2004): Variation in Giardia: implications for taxonomy and epidemiology. Adv. Parasitol., (58): 137 141. DOI: $10.1016 / S 0065-308 X(04) 58002-8$

Thompson, R.C., Palmer, C.S., O'Handeey, R. (2008): The public health and clinical significance of Giardia and Cryptosporidium in domestic animals. Vet. J., 177(1): 18 - 25. DOI: 10.1016/j. tvjl.2007.09.022

Umur, S., Meral, Y , BolukBas, C., Gurler, A., Acicl, M. (2017): First clinical Strongyloides stercoralis case in a dog in Turkey. Turk. J. Vet. Anim. Sci., 4(1): 312 - 315. DOI: 10.3906/vet-1606-2

Upjohn, M., Cobb, C., Monger, J.,Geurden, T., Claerebout, E., Fox, M. (2010): Prevalence, molecular typing and risk factor analysis for Giardia duodenalis infections in dogs in a central London rescue shelter. Vet. Parasitol., 172(3 - 4): 341 - 346. DOI: 10.1016/j. vetpar.2010.05.010

Uspensky, A.V., Peshrov, R.A Gorokhov, V.V., Gorokhova, E.V. (2011): Toxocariasis in the current context. Med. Parasitol., 2: 3 -6 (In Russian)

VerWEIJ J., Brienen E. (2003): Entamoeba histolytica infections in captive primates. Parasitol. Res., 90(2): 100 - 103 DOI: 10.1007I s00436-002-0808-z

ZUBAREVA, I.M. (2001): The main helminthiases of domestic carnivores in large cities (e.g. Novosibirsk). Author's abstract of a dissertation for the award of the degree of Candidate of Veterinary Sciences, Novosibirsk (In Russian) 